\title{
Clinical Demographic Patterns of Type 1 Diabetes in Saudi Children in Tabuk City, 2000-2010
}

\section{Laila Ahmed Albishi ${ }^{*}$, Mustafa Mohammed Altoonisi ${ }^{2}$, Sawsan Mohammed Alblewi ${ }^{1}$, Rihab Hafez Osman ${ }^{3}$, Nehal Abdugadir Ahmed², Mohammed Fararjeh4}

\author{
${ }^{1}$ Pediatric Department, Medical College, Tabuk University, Tabuk, KSA \\ ${ }^{2}$ Pediatric Department, King Salman Military Hospital, Tabuk, KSA \\ ${ }^{3}$ King Fahad Specialist Hospital, Dammam, KSA \\ ${ }^{4}$ King Abdulaziz Cardiac Center, Riyadh, KSA \\ Email:^drbishi@gmail.com, toonisi@gmail.com,swalbalawi@ut.edu.sa, leobedtfriend@yahoo.com, \\ nehal.832@hotmail.com,mohamd75@yahoo.com
}

How to cite this paper: Albishi, L.A. Altoonisi, M.M., Alblewi, S.M., Osman, R.H., Ahmed, N.A. and Fararjeh, M. (2017) Clinical Demographic Patterns of Type 1 Diabetes in Saudi Children in Tabuk City, 2000-2010. Journal of Diabetes Mellitus, 7, 41-54.

https://doi.org/10.4236/jdm.2017.72004

Received: February 24, 2017

Accepted: May 5, 2017

Published: May 8, 2017

Copyright $\odot 2017$ by authors and Scientific Research Publishing Inc. This work is licensed under the Creative Commons Attribution International License (CC BY 4.0).

http://creativecommons.org/licenses/by/4.0/

\begin{abstract}
We aimed to identify the variation in the clinical background of children diagnosed with type 1 diabetes mellitus (T1DM) at King Salman Military Hospital (KSMH), Tabuk City, Kingdom of Saudi Arabia, from 2000 to 2010. Methods: This retrospective observational study was based on the clinical records of pediatric diabetes outpatients at KSMH. All children aged $<12$ years who were diagnosed with T1DM and were followed up at the diabetes clinic from 2000 to 2010, were enrolled. The local variables associated with the clinical presentation in these patients, including age, sex, body mass index (BMI), and season of onset, were evaluated. Results: Of 313 patients recruited, female patients were predominant $(\mathrm{p}=0.002)$. The mean age of onset was 6.46 years (standard deviation, 3.02). One-third of the newly diagnosed patients were overweight (35.5\%). Diabetic ketoacidosis (DKA) was the presenting feature in $38.0 \%$ of patients, wherein female patients and those aged $0-3$ years exhibited the highest likelihood of developing DKA (odds ratio, 1.7 and 2.9, respectively). Moreover, underweight children had a greater DKA incidence than healthy, overweight, or obese children $(p=0.02)$. Conclusion: This study provides additional data on T1DM in the population of the Kingdom of Saudi Arabia. In particular, we found a female predominance at presentation as well as 2 peaks for age at onset. Moreover, the BMI was lower in younger age groups overall, but was greater in older boys. Furthermore, the DKA rates were high in younger children. Thus, our data confirm the presence of variable clinical patterns in the Kingdom of Saudi Arabia, which requires further epidemiological analysis using national registry data.
\end{abstract}




\section{Keywords}

Type 1 Diabetes, Children, Diabetic Ketoacidosis, Age, Seasonal Variation, Body Mass Index

\section{Introduction}

Type 1 diabetes mellitus (T1DM) is a lifelong heterogeneous disorder, induced by an impaired autoimmune process in most cases. This condition reportedly affects approximately 15 - 30 million individuals worldwide [1]. The incidence and clinical presentation of T1DM markedly varies among countries [2], and major efforts are ongoing to extensively characterize the epidemiology of the disease [3]. Various risk factors play a role in T1DM development, including age, sex, body mass index (BMI), and season of onset.

The incidence of T1DM continues to rapidly increase in various populations globally, with a doubling time of $<20$ years in Europe [4]. In particular, the big multi-center EURODIAB and DIAMOND studies confirmed an annual increase in the incidence of T1DM of 3.2\% and 2.8\%, respectively [5] [6]. In Saudi Arabia, an increasing number of studies on the prevalence, incidence, and clinical presentations of T1DM have confirmed the increasing rate and various other clinical patterns [7]-[12]. In a recent study, the average incidence reportedly increased to 36.99 per 100,000 individuals per year, wherein $25 \%$ of patients were aged $<5$ years and $40 \%$ had been presented with diabetic ketoacidosis (DKA) [8]. Despite such increases in the incidence of this condition, to our knowledge, no national central diabetes registry program has been established in Saudi Arabia that would facilitate documenting new cases and performing epidemiological analysis. In fact, an assessment of the clinical demographics related to the disease would certainly enhance our understanding and could facilitate the development of effective interventions during the early stage of the disease.

In the present study, we aimed to identify the clinical demographic data of the northwest region of Saudi Arabia, while focusing on identifying the significant clinical variables for T1DM.

\section{Research Design and Methods}

In this retrospective observational study, we enrolled all patients aged 6 months to 13 years diagnosed with T1DM at the pediatric diabetes clinic at King Salman Military Hospital (KSMH) between January 2000 and December 2010. Data were collected through a medical chart review. The study was approved by the Research Ethics Committee of KSMH.

\subsection{Data Collection}

The pediatric diabetes clinic is a sub-specialized clinic that cares for all children diagnosed with T1DM and type 2 diabetes mellitus (T2DM), as well as those 
with a suspected diagnosis of diabetes mellitus. Any patient who visits the clinic is required to be registered in a logbook, which served as the only precise patient record from 2000 to the start of 2004, when the standard computerized patient database was established. Patients who were overbooked, or those who were not registered in the computer were added manually if needed. All the clinic logbooks are archived in a storeroom in sequence according to date. The recorded data included name, medical number, age, diagnosis, and physician name. We ensured that each file number obtained from the logbook corresponded to the patient examined, and the non-correlated cases were excluded from the study.

\subsection{Patients}

All the patients were of Saudi origin and spoke Arabic. The sex and date of birth were recorded in all cases. Patients aged between 6 months and 12 years were recruited at the diabetes clinic during follow-up. In total, 313 pediatric patients diagnosed with T1DM were enrolled, after excluding those with T2DM ( 2 cases), neonatal diabetes ( 3 cases), secondary diabetes, and age $<6$ months ( 4 cases).

The following variables were recorded: age, date of birth, sex, weight, height, BMI, presenting diagnosis, and month and year at diagnosis. The anthropometric measures included weight $(\mathrm{kg})$, height $(\mathrm{cm})$, and BMI (calculated using the standard equation: weight $[\mathrm{kg}]$ divided by the square of height $\left.\left[\mathrm{m}^{2}\right]\right)$. The data were obtained from the CDC (2000) growth chart used at the hospital, and were plotted. Moreover, the obtained BMI data were categorized according to the CDC (2000) BMI standards criteria: BMI $<5^{\text {th }}$ percentile, underweight; BMI between $5^{\text {th }}$ and $85^{\text {th }}$ percentile, normal or healthy weight; BMI $\geq 85^{\text {th }}$ but $<95^{\text {th }}$ percentile, overweight; and BMI $\geq 95^{\text {th }}$ percentile, obese.

The diagnostic criteria for T1DM were based on the characteristic symptoms of polyuria, polydipsia, polyphagia, and weight loss in association with hyperglycemia $\geq 11.1 \mathrm{mmol} / \mathrm{L}$, glycosuria, ketonuria (urine ketone $\geq+1$ ), and the presence or absence of acidosis. Moreover, high $\mathrm{HbAlc}(>6.5 \%)$ was observed in all the patients. Autoantibody tests for immune-mediated $\beta$-cell destruction were performed in all cases with atypical presentation, including patients with presentation at age $\leq 6$ months and overweight or obese status. The insulin and C-peptide levels were also measured in these patients. Acidosis was defined according to the results of blood gas analysis ( $\mathrm{pH}$ and $\mathrm{HCO}_{3}$ ). Normal blood gas indicated the absence of DKA, whereas $\mathrm{pH}<7.3$ and $\mathrm{HCO}_{3}<15 \mathrm{mmol} / \mathrm{L}$ plus ketonuria were indicative of the presence of DKA.

\subsection{Statistical Analysis}

Poisson regression was applied to the analysis of the number of diagnosed cases according to calendar year, sex, and age. Confidence intervals (CIs) were estimated, while assuming a Poisson distribution. A likelihood ratio $\left(\chi^{2}\right)$ was used to test the significance of the terms in the model. In addition, logistic regression was used to model the presence of DKA and dichotomous seasonal presentation according to the demographic variables. Moreover, $\chi^{2}$ tests were performed to 
assess the differences in proportions between age groups, sex, weight categories, clinical presentation with DKA, and season of diagnosis. Independent-sample t-tests were used to compare the mean ages at presentation. All statistical analyses were conducted using SPSS v.20. An $\alpha$ level of 0.05 was used to indicate statistical significance.

\section{Results}

Between 2000 and 2010, a total of 313 children, aged between 6 months and 12 years, were diagnosed with T1DM at KSMH. Poisson regression of the number of diagnosed cases by year and sex indicated a significant effect of year when the variable was treated as a factor $(p=0.019)$ or as a continuous variable (relative risk, $1.05 ; 95 \% \mathrm{CI}, 1.0-1.1 ; \mathrm{p}=0.014)$. Thus, a slight increase in the number of diagnosed cases was evident over the calendar years 2000-2010 (Figure 1). Thus, a calculation of the incidence rates according to the population is warranted, as population growth over this 11-year period would be expected to account for any increase in the number of diagnosed cases.

\subsection{Age and Sex Distribution at Diagnosis}

From the whole sample, 184 were girls (58.8\%) and 129 were boys (41.2\%). The number of girls diagnosed with T1DM was significantly greater than the number of boys diagnosed with T1DM, with a female-to-male rate ratio of 1.4 (95\% CI, $1.1-1.8 ; \mathrm{p}=0.002)$.

The age of onset in the sample ranged from 0.6 to 12 years (mean, 6.46 years; standard deviation [SD], 3.02 years). The average age at onset in the girls was 6.57 years (SD, 3.02 years), although there was a subsequent characteristic peak for girls between the ages of 9 and 10 years (accounting for $24 \%$ of girls in the sample; Figure 2). The average age at diagnosis in the boys was 6.32 years (SD, 3.03 years), and the peak age was 7 years; there was no difference in the average age at diagnosis between the boys and girls $(\mathrm{t}[311]=0.72 ; \mathrm{p}=0.47)$. Moreover,

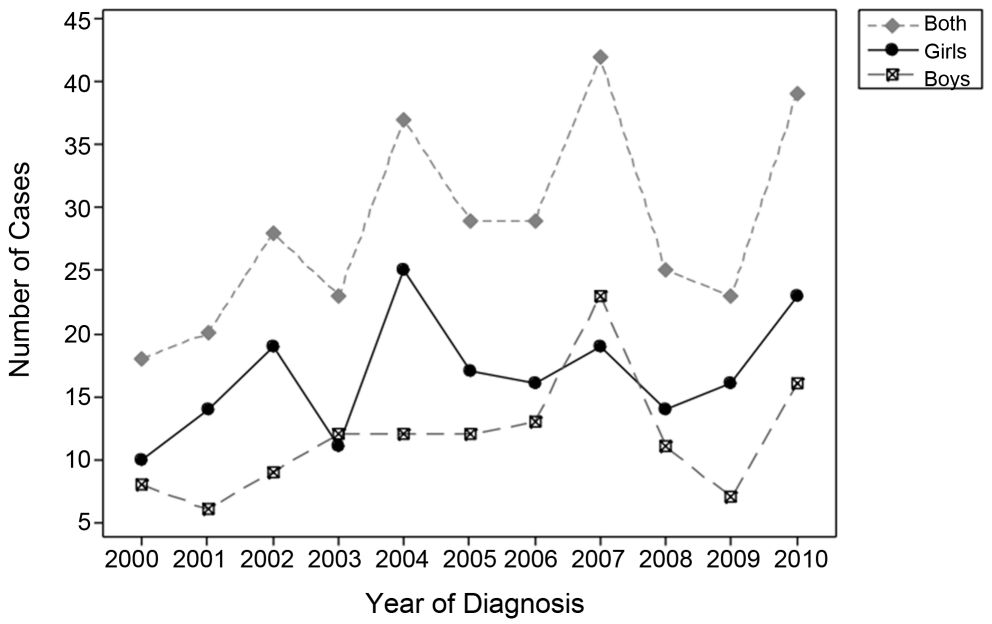

Figure 1. Number of cases Diagnosed by calendar year. 


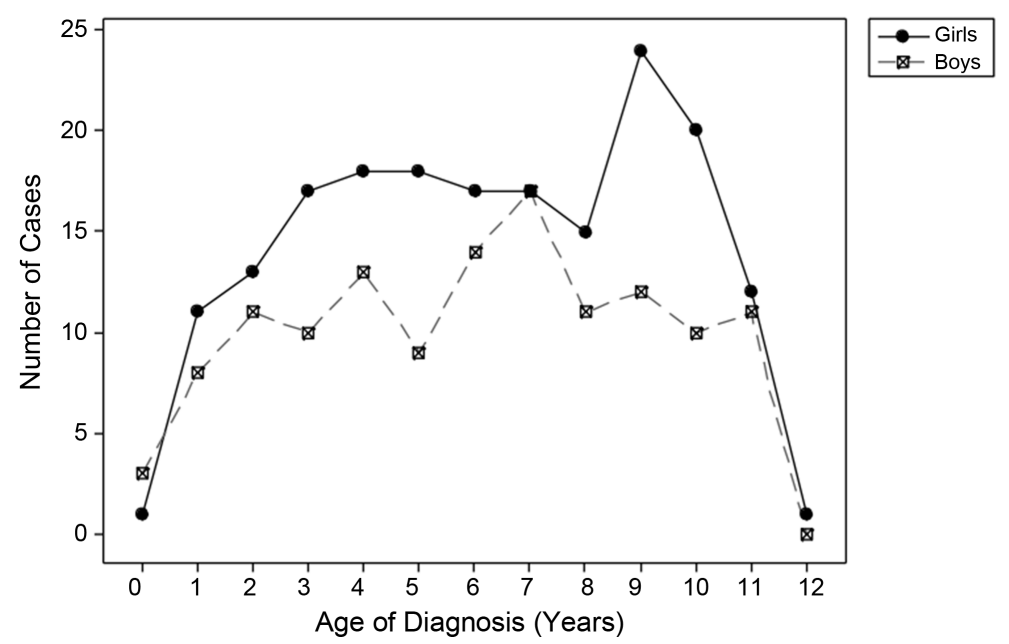

Figure 2. Number of girls and boys diagnosed by age.

there was no clinical significance of the distribution of either sex according to age category $(\mathrm{p}=0.65)$.

\subsection{BMI Classification at Diagnosis}

Children were assigned to weight categories according to their BMI percentile (Table 1$)$. Of the patients with available BMI data $(n=290)$, approximately half (55.5\%) were considered to have a healthy weight, one-third were considered to be underweight (35.5\%), and a small percentage were considered to be overweight $(4.5 \%)$ or obese $(4.5 \%)$. Due to the small number of children in the overweight or obese categories, these were subsequently collapsed into a single category for statistical analyses to ensure adequate cell sizes.

$\chi^{2}$ analyses indicated that the weight category (with overweight and obese categories combined) did not differ according to sex $\left(\chi^{2}[2]=1.28 ; \mathrm{p}=0.53\right)$ or age category $\left(\chi^{2}[6]=1.64, \mathrm{p}=0.95\right)$. Moreover, the relationships between the sample age at diagnosis, sex, and weight categories were calculated (Table 1) to indicate the distribution of weight categories according to age and sex. The age at diagnosis was divided into 4 categories, with relatively equal frequencies within the sample, and with the condition that the cutoff points fell between (and not within) the age integers. The 4 age groups and their proportions in the sample are as follows: 0 - 3 years (23.6\%), 4 - 6 years (28.4\%), 7 - 8 years (19.2\%), and 9 - 12 years $(28.8 \%)$. The distribution of patients into these age categories did not significantly differ between boys and girls $\left(\chi^{2}[3]=1.65 ; \mathrm{p}=0.65\right)$.

\subsection{DKA at Presentation}

The clinical presentation of DKA was summarized according to sex, age, and weight category (Table 2). Overall, 106 of the 279 children (38.0\%) with available data had presented with DKA. Logistic regression analysis indicated that presentation with DKA exhibited significant model effects for the age category $(p=0.04)$, sex $(p=0.046)$, and weight category $(p=0.01)$. Girls had a higher likelihood of developing DKA, with a girl-to-boy OR of 1.7 (95\% CI, $1.01-2.85$; p 
Table 1. Number of children diagnosed by age, sex, and BMI category.

\begin{tabular}{|c|c|c|c|c|c|}
\hline & $\begin{array}{c}\text { Underweight } \\
(<5 \text { th percentile })\end{array}$ & $\begin{array}{c}\text { Normal weight } \\
\text { (5th-84th percentile) }\end{array}$ & $\begin{array}{c}\text { Overweight } \\
\text { (85th-94th percentile) }\end{array}$ & $\begin{array}{c}\text { Obese } \\
(\geq 95 \text { th percentile) }\end{array}$ & ) Tota \\
\hline \multicolumn{6}{|c|}{ Boys } \\
\hline 0 - 3 years & $10(35.7 \%)$ & $16(57.1 \%)$ & $1(3.6 \%)$ & $1(3.6 \%)$ & 28 \\
\hline 4 - 6 years & $12(38.7 \%)$ & $17(54.8 \%)$ & $1(3.2 \%)$ & $1(3.2 \%)$ & 31 \\
\hline 7 - 8 years & $8(29.6 \%)$ & $15(55.6 \%)$ & $2(7.4 \%)$ & $2(7.4 \%)$ & 27 \\
\hline $9-12$ years & $9(28.1 \%)$ & $18(56.2 \%)$ & $2(6.2 \%)$ & $3(9.4 \%)$ & 32 \\
\hline Total & $39(33.1 \%)$ & $66(55.9 \%)$ & $6(5.1 \%)$ & $7(5.9 \%)$ & 118 \\
\hline \multicolumn{6}{|c|}{ Girls } \\
\hline 0 - 3 years & $13(32.5 \%)$ & $21(52.5 \%)$ & $4(10.0 \%)$ & $2(5.0 \%)$ & 40 \\
\hline 4 - 6 years & $16(33.3 \%)$ & $28(58.3 \%)$ & $2(4.2 \%)$ & $2(4.2 \%)$ & 48 \\
\hline 7 - 8 years & $14(45.2 \%)$ & $15(48.4 \%)$ & $0(0.0 \%)$ & $2(6.5 \%)$ & 31 \\
\hline $9-12$ years & $21(39.6 \%)$ & $31(58.5 \%)$ & $1(1.9 \%)$ & $0(0.0 \%)$ & 53 \\
\hline Total & $64(37.2 \%)$ & $95(55.2 \%)$ & $7(4.1 \%)$ & $6(3.5 \%)$ & 172 \\
\hline \multicolumn{6}{|c|}{ Boys and girls } \\
\hline 0 - 3 years & $23(33.8 \%)$ & 37 (54.4\%) & $5(7.4 \%)$ & $3(4.4 \%)$ & 68 \\
\hline $4-6$ years & $28(35.4 \%)$ & $45(57.0 \%)$ & $3(3.8 \%)$ & $3(3.8 \%)$ & 79 \\
\hline 7 - 8 years & $22(37.9 \%)$ & $30(51.7 \%)$ & $2(3.4 \%)$ & $4(6.9 \%)$ & 58 \\
\hline $9-12$ years & $30(35.3 \%)$ & 49 (57.6\%) & $3(3.5 \%)$ & $3(3.5 \%)$ & 85 \\
\hline Total & $103(35.5 \%)$ & $161(55.5 \%)$ & $13(4.5 \%)$ & $13(4.5 \%)$ & 290 \\
\hline
\end{tabular}

Note: Percentages are calculated within each row. BMI, body mass index.

Table 2. Number and percentage of children presenting with DKA according to sex, age, and BMI category.

\begin{tabular}{|c|c|c|c|c|c|}
\hline & \multicolumn{4}{|c|}{$\mathrm{n}(\%)$ presenting with DKA } & \multirow[b]{2}{*}{ Total } \\
\hline & Total N & $\begin{array}{c}\text { Underweight } \\
(<5 \text { th percentile) }\end{array}$ & $\begin{array}{c}\text { Normal weight } \\
\text { (5th-84th percentile) }\end{array}$ & $\begin{array}{l}\text { Overweight and obese } \\
\text { (85th percentile) }\end{array}$ & \\
\hline \multicolumn{6}{|c|}{ Boys } \\
\hline $0-3$ years & 27 & $6(60.0 \%)$ & $5(33.3 \%)$ & $1(50.0 \%)$ & $12(44.4 \%)$ \\
\hline $4-6$ years & 30 & $5(41.7 \%)$ & $1(6.2 \%)$ & $1(50.0 \%)$ & $7(23.3 \%)$ \\
\hline 7 - 8 years & 25 & $4(50.0 \%)$ & $3(23.1 \%)$ & $0(0.0 \%)$ & $7(28.0 \%)$ \\
\hline $9-12$ years & 32 & $4(44.4 \%)$ & $5(27.8 \%)$ & $0(0.0 \%)$ & $9(28.1 \%)$ \\
\hline Total & 114 & $19(48.7 \%)$ & $14(22.6 \%)$ & $2(15.4 \%)$ & $35(30.7 \%)$ \\
\hline \multicolumn{6}{|c|}{ Girls } \\
\hline $0-3$ years & 40 & $10(76.9 \%)$ & $10(47.6 \%)$ & $1(16.7 \%)$ & $21(52.5 \%)$ \\
\hline 4 - 6 years & 45 & $4(26.7 \%)$ & 7 (26.9\%) & $2(50.0 \%)$ & $13(28.9 \%)$ \\
\hline 7 - 8 years & 29 & $9(64.3 \%)$ & $4(30.8 \%)$ & $1(50.0 \%)$ & $14(48.3 \%)$ \\
\hline $9-12$ years & 51 & $7(35.0 \%)$ & $16(53.3 \%)$ & $0(0.0 \%)$ & $23(45.1 \%)$ \\
\hline Total & 165 & $30(48.4 \%)$ & $37(41.1 \%)$ & $4(30.8 \%)$ & $71(43.0 \%)$ \\
\hline \multicolumn{6}{|c|}{ Boys and girls } \\
\hline 0 - 3 years & 67 & $16(69.6 \%)$ & $15(41.7 \%)$ & $2(25.0 \%)$ & $33(49.3 \%)$ \\
\hline $4-6$ years & 75 & $9(33.3 \%)$ & $8(19.0 \%)$ & $3(50.0 \%)$ & $20(26.7 \%)$ \\
\hline 7 - 8 years & 54 & $13(59.1 \%)$ & $7(26.9 \%)$ & $1(16.7 \%)$ & $21(38.9 \%)$ \\
\hline $9-12$ years & 83 & $11(37.9 \%)$ & $21(43.8 \%)$ & $0(0.0 \%)$ & $32(38.6 \%)$ \\
\hline Total & 279 & $49(48.5 \%)$ & $51(33.6 \%)$ & $6(23.1 \%)$ & $106(38.0 \%)$ \\
\hline
\end{tabular}

Note: Percentages are calculated within each cell. BMI, body mass index. 
$=0.046)$. Children in the youngest age category $(0-3$ years $)$ also had higher rates of DKA presentation, as compared to those in the 4 -6-year age group (OR, 2.9; 95\% CI, $1.4-5.9 ; \mathrm{p}=0.004$ ). The OR between the other age categories did not significantly differ. Children classified as underweight had greater odds of DKA presentation than normal-weight children (OR, 1.9; 95\% CI, $1.1-3.2$; p $=0.02$ ) or overweight/obese children (OR, 3.3; 95\% CI, $1.2-9.2 ; \mathrm{p}=0.02)$. Although the percentage of DKA in normal-weight children was $33.6 \%$, as compared to that $(23.1 \%)$ in overweight/obese children (Table 2), the OR between these 2 groups was not statistically significant (OR, 1.8; 95\% CI, 0.6-4.8; p = 0.27 ). The addition of multiplicative terms between the 3 variables to the equation did not yield any significant interaction effects.

\subsection{Seasonal Variation at Diagnosis}

The number of cases diagnosed according to each month of the year is presented in Figure 3. A U-shaped trend was observed, wherein a greater number of cases were diagnosed in the autumn and winter months than in the spring or summer. The peak month for diagnosis was November (13.7\% of the cases), whereas the trough was observed in July (5.0\%).

Table 3 demonstrates the number and percentage of cases diagnosed in the 4 seasons according to age and sex. A significantly greater proportion of cases had presented in winter and autumn than in spring or summer $\left(\chi^{2}[3]=12.99 ; \mathrm{p}=\right.$ 0.005). In fact, $60.3 \%$ of patients were diagnosed in autumn/winter (95\% CI, 0.55 - 0.66 ), as compared to $39.7 \%$ of patients who were diagnosed in spring/summer (95\% CI, $0.34-0.45 ; \mathrm{p}<0.001$ ). This trend for autumn/winter presentation was evident in all the age groups ( $0-3$ years: $65.2 \%, 4-6$ years: $57.6 \%, 7-8$ years: $57.6 \%$, and $9-12$ years: $60.3 \%$; $\mathrm{p}=0.77)$. The autumn/winter pattern of presentation did not vary according to BMI classification $(\mathrm{p}=0.52)$ or DKA presentation $(\mathrm{p}=0.49)$.

There was a significant difference in the seasonal proportion of cases according to sex, with $67.7 \%$ of boys (95\% CI, 59\% - 75\%) being diagnosed in autumn/

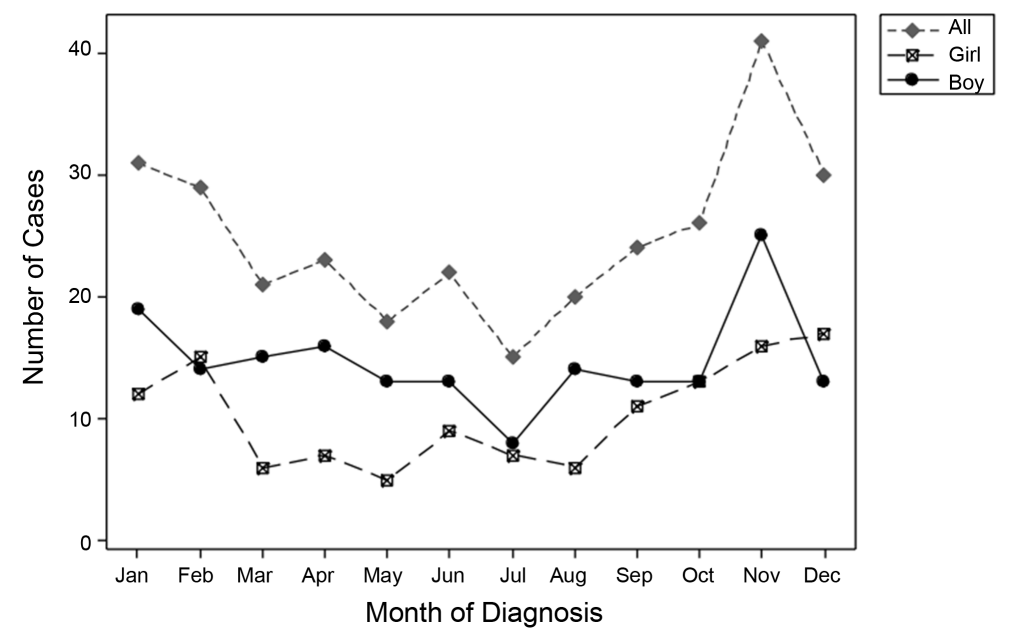

Figure 3. Number of cases diagnosed by calendar month. 
Table 3. Number of children diagnosed by age, sex, and season.

\begin{tabular}{|c|c|c|c|c|c|}
\hline & Winter (Dec-Feb) & Spring (Mar-May) & Summer (Jun-Aug) & Autumn (Sep-Nov) & Total \\
\hline \multicolumn{6}{|c|}{ Boys } \\
\hline $0-3$ years & $9(30.0 \%)$ & $3(10.0 \%)$ & $6(20.0 \%)$ & $12(40.0 \%)$ & 30 \\
\hline $4-6$ years & $12(34.3 \%)$ & $4(11.4 \%)$ & $6(17.1 \%)$ & $13(37.1 \%)$ & 35 \\
\hline 7 - 8 years & $9(33.3 \%)$ & 7 (25.9\%) & $3(11.1 \%)$ & $8(29.6 \%)$ & 27 \\
\hline $9-12$ years & $14(43.8 \%)$ & $4(12.5 \%)$ & $7(21.9 \%)$ & $7(21.9 \%)$ & 32 \\
\hline Total & $44(35.5 \%)$ & $18(14.5 \%)$ & $22(17.7 \%)$ & $40(32.3 \%)$ & 124 \\
\hline \multicolumn{6}{|c|}{ Girls } \\
\hline $0-3$ years & $9(23.1 \%)$ & 7 (17.9\%) & $8(20.5 \%)$ & $15(38.5 \%)$ & 39 \\
\hline 4 - 6 years & $14(28.0 \%)$ & $13(26.0 \%)$ & $13(26.0 \%)$ & $10(20.0 \%)$ & 50 \\
\hline 7 - 8 years & $6(18.8 \%)$ & $10(31.2 \%)$ & $5(15.6 \%)$ & $11(34.4 \%)$ & 32 \\
\hline $9-12$ years & $17(30.9 \%)$ & $14(25.5 \%)$ & $9(16.4 \%)$ & $15(27.3 \%)$ & 55 \\
\hline Total & $46(26.1 \%)$ & $44(25.0 \%)$ & $35(19.9 \%)$ & $51(29.0 \%)$ & 176 \\
\hline \multicolumn{6}{|c|}{ Boys and girls } \\
\hline 0 - 3 years & $18(26.1 \%)$ & $10(14.5 \%)$ & $14(20.3 \%)$ & 27 (39.1\%) & 69 \\
\hline 4 - 6 years & $26(30.6 \%)$ & 17 (20.0\%) & 19 (22.4\%) & $23(27.1 \%)$ & 85 \\
\hline 7 - 8 years & $15(25.4 \%)$ & $17(28.8 \%)$ & $8(13.6 \%)$ & $19(32.2 \%)$ & 59 \\
\hline $9-12$ years & $31(35.6 \%)$ & $18(20.7 \%)$ & $16(18.4 \%)$ & $22(25.3 \%)$ & 87 \\
\hline Total & 90 (30.0\%) & $62(20.7 \%)$ & 57 (19.0\%) & $91(30.3 \%)$ & 300 \\
\hline
\end{tabular}

Note: Percentages are calculated within each cell.

winter as compared to $55.1 \%$ of girls ( $95 \% \mathrm{CI}, 48 \%-62 \%)$. The male-to-female OR was found to be 1.7 (95\% CI, $1.1-2.8 ; \mathrm{p}=0.03)$.

\section{Discussion}

In the present study, we found that the T1DM incidence is higher in females than in males $(p=0.002)$, in contrast with other studies that showed an average equal distribution between girls and boys [13].

Moreover, there was an increasing trend in the number of new cases during the 11-year study period, with the highest number of new cases added in 2007. Nevertheless, it is essential to consider the number of individuals in the population at risk in order to correctly estimate the incidence. A population-based registry would be ideal to determine such values. Moreover, a variable pattern of increase in the same population is also observed, which might reflect ethnic differences (including both genetic and lifestyle factors) [14], differences in BMI [15], and area characteristics related to exposure to infections such as child population density, deprivation, urban-rural status, and remoteness [10]. In the present study, there were 2 peaks for age at diagnosis, one at $6-6.5$ years that is comparable to the peak of onset observed in other studies [16] and another at 9 10 years in girls, which supports the hypothesis that the incidence would in- 
crease at puberty due to the associated sex effect [17].

Furthermore, we found that the BMI at diagnosis did not markedly increase in patients with T1DM, but was instead lower in younger age groups. In contrast, the BMI was greater ( $\geq 95$ th percentile) in older male children. This may be explained by the "accelerator hypothesis", wherein BMI and changes in weight have been proven to be inversely related to the age at diagnosis of T1DM [18] [19] [20] [21] [22]. To our knowledge, this is the first study to explore the relationship of BMI in the newly diagnosed cases. Similar findings have been observed in a large series of children and adolescents, wherein a steady increase in BMI was observed in newly diagnosed T1DM cases; these observations support the accelerator hypothesis and emphasize the contribution of increasing BMI to the conspicuous increase in the incidence rate of T1DM in children aged $<15$ years [23].

Moreover, DKA at presentation was found to be associated with the age category $(p=0.04)$, sex $(p=0.046)$, and weight category $(p=0.01)$, with a female predominance, as indicated in previous studies [7] [24]. DKA was observed at presentation in $38 \%$ of cases overall, consistent with the study of Schober et al. on the Australian population and with the study of Abdul-Rasoul on Kuwaiti children [25] [26]. The patients in the younger age (0 - 3 years) category had higher DKA presentation rates, which is similar to that noted in a Finnish nationwide study, wherein the frequency of DKA in children aged $<2$ years was as high as $53.3 \%$ [27]. Hence, it may be important to consider the increased frequency and severity of DKA at presentation in younger age groups. This unique presentation may be explained by the fact that this category has a higher rate of respiratory and gastrointestinal infections, which could delay the diagnosis [28] [29]. Furthermore, underweight patients had a higher rate of DKA, which confirms its association with severely low $\beta$-cell function, as well as low serum $C$ peptide concentrations, and indicates the presence of a small absolute $\beta$-cell mass and more aggressive $\beta$-cell destruction in infants and young children [30].

The seasonality of diagnosis was found to correspond with a sinusoidal model [31] [32], with a peak occurring in winter (13.7\% of the cases) and a trough in July (5.0\%). This peak was consistently observed in both sexes and in all age groups [4], with moderate heterogeneity in the seasonal distribution among patients; in fact, $60.3 \%$ and $39.7 \%$ of patients were diagnosed in autumn/winter (95\% CI, 0.55 - 0.66) and spring/summer (95\% CI, $0.34-0.45$; p < 0.001), respectively. The seasonal variation of onset was interpreted as an expression of the precipitating factors of the disease, such as infection and cold climate [33] [34].

Nevertheless, the present study had certain limitations. First, the study was conducted on a target population, rather than the entire population. Therefore, the results obtained cannot be generalized to the entire population. However, the findings may facilitate further research on children with T1DM in the Tabuk region. Second, this descriptive study assessed basic demographic census data (age, 
sex, BMI, presenting diagnosis, and seasonal variation at diagnosis) in a defined population using the chart review method; however, medical charts are likely to have missing information or unreadable notes by health service providers. Third, the CDC growth chart may not be ideal for use in Saudi children, as it could affect the results of the weight category. Finally, the selection of the upper cutoff age group in the study (i.e., 12 years) prevents the detection of many patients diagnosed during the pubertal period, which would contribute to a higher peak for the age at diagnosis.

\section{Conclusion}

In the 11-year study (2000-2010), various clinical variables were explored. There was an increase in the number of T1DM cases throughout the study period, with a marked increase in children, as proven in many studies [35] [36] [37]. The DKA presentation rates were similar to those of other reports from the Gulf regions and other areas in Saudi Arabia [25]-[37]. The presence of a higher body weight at diagnosis may encourage further preclinical studies to assess whether the accelerated $\beta$-cell apoptosis is due to insulin resistance in the pathogenesis of T1DM [38]. The seasonality of T1DM is a real phenomenon, and appears to be dependent on the geographical location [39]. Finally, we recommend that a systematic review of the Middle East population to analyze these variables, and comparison with those of western studies, could help establish the appropriate epidemiological factors for T1DM in children.

\section{Declarations}

\subsection{Ethics Approval}

Ethical permission for this study was granted by the Ethics Committee of KSMH (grant number R\&REC2016-117). The approval included the research protocol, data collection sheets that constitute the consent for participant agreement, progress, and the final report submitted at the end of the study.

\subsection{Consent for Publication}

All patients agreed individually (indicated via a written consent form).

\subsection{Availability of Data and Materials}

All raw data are available as Excel sheets that are uploaded as supplementary files for review, if needed.

\section{Conflict of Interests}

The authors stated that they have no conflict of interests.

\section{Funding}

No funding body played a role in this study design, analysis, or writing of the manuscript. 


\section{Author Contributions}

L. A. Albishi formulated the study design and outline of the data for analysis, wrote the initial and final drafts of the paper, and organized the references. $\mathrm{M}$. M. Altoonisi contributed to the text of the document, revision all of the contributions to the paper from the other authors, and read and approved the final manuscript. S. M. Alblewi was responsible for determining the focus, type and analysis of data to be extracted. R. H. Osman contributed to the design and presentation of the data and reviewed the contribution of the statistician. M. Fararjeh and N. A. Ahmed contributed to the revision of the final manuscript. Dr. Fisher was the statistician who performed the analyses for the manuscript, with the approval of the other authors. All authors read and approved the final manuscript.

\section{Acknowledgements}

The authors extend their appreciation and thanks to the nursing staff of the pediatric clinics, particularly Ms. Ageelah Hadi Alhumami and Ms. Fatimah Mohammad Alkaabi for their assistance with data preparation, and Dr. Fisher for his statistical analysis and considerable input in the study.

\section{References}

[1] Barker, J.M., Goehrig, S.H., Barriga, K., Hoffman, M., Slover, R., Eisenbarth, G.S., Norris, J.M., Klingensmith, G.J. and Rewers, M. (2004) Clinical Characteristics of Children Diagnosed with Type 1 Diabetes through Intensive Screening and Follow-Up. Diabetes Care, 27, 1399-1404. https://doi.org/10.2337/diacare.27.6.1399

[2] Maahs, D.M., West, N.A., Lawrence, J.M. and Mayer-Davis, E.J. (2010) Chapter 1: Epidemiology of Type 1 Diabetes. Endocrinology and Metabolism Clinics of North America, 39, 481-497. https://doi.org/10.1016/j.ecl.2010.05.011

[3] Patterson, C., Guariguata, L., Dahlquist, G., Soltesz, G., Ogle, G. and Silink, M. (2013) Diabetes in the Young-A Global View and Worldwide Estimates of Numbers of Children with Type 1 Diabetes. Diabetes Research and Clinical Practice, 103 161-175. https://doi.org/10.1016/j.diabres.2013.11.005

[4] Gale, E.A.M. (2002) The Rise of Childhood Type 1 Diabetes in the 20th Century. Diabetes, 51, 3353-3361. https://doi.org/10.2337/diabetes.51.12.3353

[5] Green, A., Patterson, C.C. and EURODIAB TIGER Study Group. Europe and Diabetes (2001) Trends in Incidence in Childhood-Onset Diabetes in Europe 19891998. Acta Diabetologica, 44, B3-B9. https://doi.org/10.1007/PL00002950

[6] DIAMOND Project Group (2006) Trends in the Incidence of Childhood Type 1 Diabetes Worldwide 1990-1999. Diabetes Medicine, 23, 857-866. https://doi.org/10.1111/j.1464-5491.2006.01925.x

[7] Al-Magamsi, M.S., Halabi, S., Eid, I.M., Shalaby, S. and Bakoush, O. (2001) High Incidence of Childhood Type 1 Diabetes in Al-Madinah, North West Saudi Arabia (2004-2009). Pediatric Diabetes, 12, 676-681.

[8] Abduljabbar, M.A., Aljubeh, J.M., Amalraj, A. and Cherian, M.P. (2010) Incidence Trends of Childhood Type 1 Diabetes in Eastern Saudi Arabia. Saudi Medical Journal, 31, 413-418.

[9] Habib, H.S. (2005) Frequency and Clinical Characteristics of Ketoacidosis as Onset 
of Childhood Type 1 Diabetes Mellitus in Northwest Saudi Arabia. Saudi Medical Journal, 12, 1936-1939.

[10] Salman, H., Abanamy, A., Ghassan, B. and Khalil, M. (2009) Childhood Diabetes in Saudi Arabia. Diabetic Medicine, 8, 176-178. https://doi.org/10.1111/j.1464-5491.1991.tb01567.x

[11] Al-Mendalawi, M.D. and Al-Herbish, A. (2009) Prevalence of Type 1 Diabetes Mellitus in Saudi Arabian Children and Adolescents. Saudi Medical Journal, 30, 310.

[12] Al-Herbish, A.S., El-Mouzan, M.I., Al-Salloum, A.A., Al-Qurachi, M.M. and AlOmar, A.A. (2008) Prevalence of Type 1 Diabetes Mellitus in Saudi Arabian Children and Adolescents. Saudi Medical Journal, 29, 1285-1288.

[13] Al-Magamsi, M.S. and Habib, H.S. (2004) Clinical Presentation of Childhood Type 1 Diabetes Mellitus in the Al-Madina Region of Saudi Arabia. Pediatric Diabetes, 5 , 95-98. https://doi.org/10.1111/j.1399-543X.2004.00046.x

[14] Kulaylat, N.A. and Narchi, H. (2000) A Twelve Year Study of the Incidence of Childhood Type 1 Diabetes Mellitus in the Eastern Province of Saudi Arabia. Journal of Pediatric Endocrinology and Metabolism, 13, 135-140.

https://doi.org/10.1515/jpem.2000.13.2.135

[15] Salman, H. (1992) Type I Diabetes in Children in Riyadh: Seasonal Variation. Diabetes Medicine, 9, 780-781.

[16] Soltesz, G., Patterson, C.C., Dahlquist, G. and EURODIAB Group (2007) Worldwide Childhood Type 1 Diabetes Incidence-What Can We Learn from Epidemiology? Pediatric Diabetes, 8, 6-14.

[17] Neu, A., Willasch, A., Ehehalt, S., Kehrer, M., Hub, R. and Ranke, M.B. (2001) Diabetes Incidence in Children of Different Nationalities: An Epidemiological Approach to the Pathogenesis of Diabetes. Acta Diabetologica, 44, B21-B26. https://doi.org/10.1007/PL00002948

[18] Waldhör, T., Schober, E., Rami, B. and The Austrian Diabetes Incidence Study Group (2003) Regional Distribution of Risk for Childhood Diabetes in Austria and Possible Association with Body Mass Index. European Journal of Pediatrics, 162, 380-384.

[19] Giménez, M., Aguilera, E., Castell, C., De Lara, N., Nicolau, J. and Conget, I. (2007) Relationship between BMI and Age at Diagnosis of Type 1 Diabetes in a Mediterranean Area in the Period of 1990-2004. Diabetes Care, 30, 1593-1595. https://doi.org/10.2337/dc06-2578

[20] Kibirige, M., Metcalf, B., Renuka, R. and Wilkin, T.J. (2003) Testing the Accelerator Hypothesis: The Relationship between Body Mass and Age at Diagnosis of Type 1 Diabetes. Diabetes Care, 26, 2865-2870.

[21] Betts, P., Mulligan, J., Ward, P., Smith, B. and Wilkin, T. (2005) Increasing Body Weight Predicts the Earlier Onset of Insulin-Dependent Diabetes in Childhood: Testing the "Accelerator Hypothesis". Diabetes Medicine, 22, 144-151. https://doi.org/10.1111/j.1464-5491.2004.01368.x

[22] Pundziute-Lycka, A., Persson, L.A., Cedermark, G., Jansson-Roth, A., Nilsson, U., Westin, V. and Dahlquist, G. (2004) Diet, Growth, and the Risk for Type 1 Diabetes in Childhood: A Matched Case-Referent Study. Diabetes Care, 27, 2784-2789. https://doi.org/10.2337/diacare.27.12.2784

[23] Wolf, J., Reinehr, T., Stachow, R., Grabert, M., Schober, E., Rascher, W., Holl, R.W. and DPV Scientific Initiative of Germany and Austria (2005) The "Accelerator Hypothesis": Relationship between Weight, Height, Body Mass Index and Age at Diagnosis in a Large Cohort of 9,248 German and Austrian Children with Type 1 Di- 
abetes Mellitus. Acta Diabetologica, 48, 2501-2504.

[24] Schober, E., Rami, B. and Waldhoer, T. (2010) Diabetic Ketoacidosis at Diagnosis in Austrian Children in 1989-2008: A Population-Based Analysis. Acta Diabetologica, 53, 1057-1061. https://doi.org/10.1007/s00125-010-1704-1

[25] Abdul-Rasoul, M., Al-Mahdi, M., Al-Quttan, H., Al-Tarkait, N., Alhkouly, M., Al-Safi, R., Al-Shawaf, F. and Mahmoud, H. (2010) Ketoacidosis at Presentation of Type 1 Diabetes in Children in Kuwait: Frequency and Clinical Characteristics. Pediatric Diabetes, 12, 351-356.

[26] Hekkala, A., Reunanen, A., Koski, M., Knip, M., Veijola, R. and for the Finnish Pediatric Diabetes Register (2010) Age-Related Differences in the Frequency of Ketoacidosis at Diagnosis of Type 1 Diabetes in Children and Adolescents. Diabetes Care, 33, 1500-1502. https://doi.org/10.2337/dc09-2344

[27] Nimri, R., Phillip, M. and Shalitin, S. (2007) Children Diagnosed With Diabetes During Infancy Have Unique Clinical Characteristics. Hormone Research, 67, 263267.

[28] Kulmala, P., Savola, K., Lounamaa, R., Ilonen, J., Reijonen, H., Knip, M. and Akerblom, H.K. (1999) Clinical, Autoimmune, and Genetic Characteristics of Very Young Children with Type 1 Diabetes. Childhood Diabetes in Finland (DiMe) Study Group. Diabetes Care, 22, 1950-1955. https://doi.org/10.2337/diacare.22.12.1950

[29] Al-Mahdi, M., Al-Qattan, H., Al-Tarkait, N., Alkhouly, M., Al-Safi, R., Al-Shawaf, F. and Mahmoud, H. (2010) Ketoacidosis at Presentation OF Type 1 Diabetes in Children in Kuwait: Frequency and Clinical Characteristics. Pediatric Diabetes, 11, 351-356.

[30] Komulainen, J., Lounamaa, R., Knip, M., Kaprio, E.A. and Akerblom, H.K. (1996) Ketoacidosis at the Diagnosis of Type 1 (Insulin Dependent) Diabetes Mellitus Is Related to Poor Residual Beta Cell Function. Childhood Diabetes in Finland Study Group. Archives of Disease in Childhood, 75, 410-415. https://doi.org/10.1136/adc.75.5.410

[31] Kalliora, M.I., Vazeou, A., Delis, D., Bozas, E., Thymelli, I. and Bartsocas, C.S. (2011) Seasonal Variation of Type 1 Diabetes Mellitus Diagnosis in Greek Children. Hormones, 10, 67-71. https://doi.org/10.14310/horm.2002.1294

[32] Karvonen, M., Tuomilehto, J., Virtala, E., Pitkäniemi, J., Reunanen, A., Tuomilehto-Wolf, E. and Akerblom, H.K. (1996) Seasonality in the Clinical Onset of Insulin-Dependent Diabetes Mellitus in Finnish Children. Childhood Diabetes in Finland (DiMe) Study Group. American Journal of Epidemiology, 143, 167-176.

[33] Samuelsson, U., Carstensen, J., Löfman, O. and Nordfeldt, S. (2007) Seasonal Variation in the Diagnosis of Type 1 Diabetes in South-East Sweden. Diabetes Research and Clinical Practice, 76, 75-81.

[34] Chang, Y. and Murphy, K.M. (2002) The Epidemiology of Type 1 Diabetes in Children in Philadelphia 1990-1994: Evidence of An Epidemic. Diabetes Care, 25, 1969-1975. https://doi.org/10.2337/diacare.25.11.1969

[35] Patterson, C.C., Dahlquist, G., and EURODIAB Study Group (2007) Worldwide Childhood Type 1 Diabetes Incidence-What Can We Learn From Epidemiology? Pediatric Diabetes, 8, 6-14. https://doi.org/10.1111/j.1399-5448.2007.00280.x

[36] Patterson, C.C., Dahlquist, G.G., Gyurus, E., Green, A. and Soltesz, G. (2009) Incidence Trends for Childhood Type 1 Diabetes in Europe during 1989-2003 and Predicted New Cases 2005-20: A Multicentre Prospective Registration Study. The Lancet, 373, 2027-2033. 
[37] Razavi, Z. (2010) Frequency of Ketoacidosis in Newly Diagnosed Type 1 Diabetic Children. Oman Medical Journal, 12, 114-117. https://doi.org/10.5001/omj.2010.31

[38] Fourlanos, S., Harrison, L.C. and Colman, P.G. (2008) The Accelerator Hypothesis and Increasing Incidence of Type 1 Diabetes. Current Opinions in Endocrinology, Diabetes, and Obesity, 15, 321-325. https://doi.org/10.1097/MED.0b013e3283073a5a

[39] Moltchanova, E.V., Schreier, N., Lammi, N. and Karvonen, M. (2009) Seasonal Variation of Diagnosis of Type 1 Diabetes Mellitus in Children Worldwide. Diabetes Medicine, 26, 673-678. https://doi.org/10.1111/j.1464-5491.2009.02743.x

Submit or recommend next manuscript to SCIRP and we will provide best service for you:

Accepting pre-submission inquiries through Email, Facebook, LinkedIn, Twitter, etc. A wide selection of journals (inclusive of 9 subjects, more than 200 journals) Providing 24-hour high-quality service User-friendly online submission system Fair and swift peer-review system Efficient typesetting and proofreading procedure Display of the result of downloads and visits, as well as the number of cited articles Maximum dissemination of your research work

Submit your manuscript at: http://papersubmission.scirp.org/ Or contact jdm@scirp.org 